\title{
Knowledge Transfer in Creative Industrial Cluster : Mechanism and Countermeasures
}

\author{
LIU Shouxian \\ School of Economics and Management \\ Beijing Institute of Graphic Communication \\ Beijing, China \\ shouxianliu@163.com \\ China Center for Industrial Security Research \\ Beijing Jiaotong University \\ Beijing, China \\ shouxianliu@163.com
}

\begin{abstract}
The potential developing mode of creative industry is cluster. And it is essential for creative industrial cluster promoting knowledge transfer to create knowledge advantage of cluster. Based on congregation of creative industry and knowledge transfer, this paper clarifies the characters of knowledge transfer in creativity industry cluster, and analyzes the mechanisms in creativity industry cluster from four sides: nodes, conduits, knowledge re-source and innovational environment of cluster. At last, this paper brings up some countermeasures to promote knowledge transfer within creativity industry cluster.
\end{abstract}

Keywords- creative industry; cluster; knowledge transfer

\section{INTRODUCTION}

In the background of the economic globalization and regional integration, as the region's most active economic subject, industry cluster is increasingly becoming the core organizers of regional economic activity. In recent years, with the development of culture creative industry also showing the characteristics of gathering, creative industrial cluster (chuang yi chan ye ji ju qu, CCJQ) is playing a more and more important demonstration and leading role, promoting cultural creative industry upgrading and developing [1]. Cultural creative products derive from the inspiration, imagine, knowledge, technology and experience of culture creative people, so the industry itself is a knowledge intensive industry. CCJQ is the ideal place where the creativity and knowledge is created, and the stock of static knowledge was clearly not the sources of competitive advantage of cluster. Only through internal knowledge transfer and flow of CCJQ, CCJQ can rapidly expand the stock of knowledge of cluster, avoid the internal repeated investment in cluster, and form continuous learning atmosphere and mechanism, so as to enhance the sustainable competitiveness of the cluster. Therefore, the effective spill, fusion, sharing and transfer of internal knowledge in CCJQ, will be the key of obtaining competitive advantage and sustainable development.

\section{CREATIVE INDUSTRIAL CLUSTER: CARRIER OF KNOWLEDGE TRANSFER}

\section{A. The Meaning and Features of Creative Industrial Cluster}

Traditionally, definition of creativity industry originates from England, which is the industry that stems from individual creativity and skills and talent, through the generation and access of the intellectual property rights, having the potential to create wealth and increase the employment [2]. Later, the definition of the culture creative industries by some scholars and institutions are extended in different levels. This article believes that, the core of culture creative industry is human creativity, and with cultural content and creative achievements as its carrier, intellectual property rights protection as the means, aiming to promote social culture progress and to increase wealth.

The practices of countries all over the world show that, there are inherent principles of the development of cluster of creative industry, so that CCJQ emerges logically. CCJQ may be defined as, an organizational network is composed of creative firms and support actors which are adjacent to and relevant each other, coming into being in accordance with division and coordination and maintaining frequent interaction among actors. The features of CCJQ are as follows, the combination of creative people's living place and working environment, the combination of creativity production and consumption, diverse conglomeration environment, uniquely local characteristics, and closely connected relationship with the outside.

\section{B. Internal Knowledge and Knowledge Transfer in Creative Industrial Cluster}

Davenport and Prusak(1998) pointed that knowledge is complex, including structural experience, valuable and coded information [3]. Knowledge exists not only in documents and storage system, but also is contained in the mind of people and organizational routines. In CCJQ, internal knowledge characterizes the cultural creativity, originality, 
designing idea as the core, reflecting the integration of culture, economic and technology.

The basis of the knowledge transfer process is the practices of individuals' tacit knowledge conversion into organizational explicit knowledge. According to the knowledge conversion theory, proposed by Polyani(1966) [4], the most common types of knowledge - tacit and explicit - should be converged and evolved to create more applicable forms of knowledge based on the individuals' collaborative practices. The explicit knowledge is the ideas and knowledge which can be coded and written expressed, usually appearing as the forms of patent, technology, design and the other. Tacit knowledge is highly individual knowledge, relevantly practical and not clearly expressed. Tacit knowledge usually exists in the forms of personal experience, team understanding, technical know-how, organization culture and others. Internal knowledge in CCJQ characterizes creativity, inspiration and originality highly depending on personalized individual capacity and skills. Thus, internal knowledge in CCJQ mainly exists in the form of tacit knowledge.

Knowledge transfer is the process through which one network member is affected by the experience of another [5]. Knowledge transfer manifests itself through changes in knowledge or performance of the recipient unit. In CCJQ, knowledge transfer characterizes explicit knowledge transfer exhibiting in physical form and tacit knowledge transfer being carried embedding in activities of people. For one side, the tangible physical form of creativity and originality is creative products. For another side, coded and textual form is the technology of the patent. Explicit knowledge transfers and shares in CCJQ, through transaction and display of creative products in the cluster and sharing of technology patents. The process of tacit knowledge transfer in CCJQ is compose of communicating and thinking collisions among individuals in the creative enterprise and sharing of opinions between staffs within the various units of research institutions, intermediaries, public sector.

\section{Creative Industrial Cluster: Effective Carrier of Internal Knowledge Transfer}

On the one part, CCJQ can effectively promote the spillover and transfer of their internal knowledge. Large number of creators and creative designers engages in the same or similar work, creative enterprises, research institutions and other relevant organizations conglomerates in CCJQ. And the adjacent location contributes to the creative ideas and technical know-how exchange between the main actors, engendering the effect of knowledge spillover in cluster. Transferring and sharing of spillover knowledge between knowledge transmitters and knowledge recipients forms the knowledge transfer process. Tacit knowledge, inheriting in minds of creators, and rooted in specific social context, is more important for development of culture creative industry and can be effective transferred through face-to-face communication between individual and personal practice. CCJQ provides much more conveniently ways of communication and open atmosphere for internal actors, so as to effectively promote internal knowledge in cluster, especially tacit knowledge transfer.

On the other part, internal knowledge transfer can effectively promote the innovation and upgrading of CCJQ. The internal innovation behavior in cluster originates from the collision of thinking, brain storming and knowledge sharing. Knowledge is a special resource, not the same as land, labor and other physical resources which have the properties of diminishing marginal utility. Sharing and flow of knowledge can bring the multiplier effect of growth. Therefore, knowledge transfer can quickly thicken the overall stock of knowledge in cluster and strengthen learning capacity of actors in cluster, and therefore enhance innovative competitiveness and upgrading of CCJQ.

\section{KNOWLEDGE TRANSFER Mechanism OF CREATIVE INDUSTRIAL CLUSTER}

The basic elements of knowledge transfer within industrial cluster involve the main nodes of knowledge network, the relationship chain between each node in the cluster as well as flowing innovative resources in network. At the same time, knowledge innovative environment also has important influence on internal knowledge transfer in cluster.

In CCJQ, actors and institutions, such as culture creative enterprises, universities and research institutions, ser-vice agencies, government and public sector, financial institutions, which have been established network interactive relationship, constitute the overall knowledge transfer mechanism of CCJQ. Specifically, knowledge transfer nodes include creative enterprises, universities and research institutions, government and public sector, service agencies, and financial institutions. And two-way connections between nodes represent conduits of sharing and flowing of creativity, information, technology, policy and other knowledge resources between nodes. Therefore, from four aspects above, this article will respectively discuss the internal knowledge transfer mechanism in CCJQ.

\section{A. Knowledge Transfer Nodes}

Knowledge transfer nodes mainly include the following five actors - creative enterprises, universities and research institutions, intermediary service organizations, government and public sector, and financial institutions.

1) Creative Enterprise. Creative Enterprises include culture creativity products manufacturers, and the manufacturers of culture creativity product related components, distributors and service providers, etc. Among them, the upstream of culture creative industry chain is creativity products manufacturers and the lower reaches of industry chain is product sales and service providers. Both are main bodies of knowledge transfer mechanism in CCJQ. Creative enterprises are mostly founded by the creative genius, the artist and highly skilled people, and have small business employees, respectively (mostly 3 or 4), highlighting the creativity of the individual. Therefore, the culture creative enterprises are mostly SMEs(small and middle enterprise, SME) [6]. 
2) University and Research Institutions. They are support institutions for knowledge transfer. They not only can create new ideas, new knowledge and new technology, but also can promote knowledge diffusion and commercialization by the education, training and achievements conversion, etc. They are the main participants in the internal knowledge innovation and innovative subject in CCJQ.

3) Intermediary Service Organizations. They include industry associations, chambers of commerce, business service centers, law firms, accounting firms and other forms of intermediary organizations existing in the CCJQ. These intermediaries have professional advantage in a certain area. And the most creative enterprises in CCJQ are small and medium-sized, and request professional support of intermediary institutions in the aspects of creativity transformation, product development and marketing. Intermediary service organizations connect among actors to promote enterprise network ties and to integrate the combination of government, manufactories, research institutions and universities.

4) Government and Public Sectors. Exchange of knowledge in CCJQ can't just rely on market, because the market can't ensure to form mechanisms which enhance knowledge innovation. The government makes up for the market defects through the policy effect and public products supply. Internal knowledge exchange in CCJQ requires active participation and coordination of government, organically integrating the creative talent, professional institutions and enterprises to develop and integrate more creative knowledge.

5) Financial Institutions. Financial Institutions include commercial banks, investment companies, trusts and other actors. Culture creative enterprises in cluster require financial support in process of knowledge creation and technological design. The majority of SMEs characterizes early phases of business circle, high risk, low benefit ratio, immature market prestige, strong demand for capital and information. Financial institutions have financial intermediation, loan information and specialized financial knowledge that is necessary for culture creative enterprises and other institutions.

\section{B. the Conduits of Knowledge Transfer}

The conduits of knowledge transfer In CIC are the channels through which actors maintain relations and communicate each other, and through which internal information and valuable knowledge of cluster transfers and diffuses somewhere. Through the conduits, CIC could add value to creativity, information and technological knowledge in process of transferring. In CIC, some conduits are dominant including conduits between creative firms (e.g. between different sectors of industry chain, between customers and creative firms, and between competitors and cooperators), between creative firms and scientific research institutions, and between creative firms and medium institutions. And the other conduits of knowledge transfer are secondary such as conduits between government, medium and other institutions. The conduits are set up actually through the process of diffusing knowledge among actors (nudes). In CIC, partially valuable knowledge transfers through formal channels, and more important knowledge diffuses through informal channels, through which effectiveness and speed of diffusing and transferring is better than the frontier. Especially, informal communication promotes tacit knowledge transfer among all actors in CIC, and makes innovative capacity of creative enterprises and total cluster advances to the higher class [7].

\section{Knowledge Resources}

In fact, CCJQ is the aggregate of creativity, technology, patents and other knowledge resources, in which tacit knowledge account for a large proportion. Knowledge network in cluster has more advantages in the allocation of resources and allocation efficiency. Internal enterprises and other agents in CCJQ use a variety of channels for knowledge acquisition, absorption, utilization and novel knowledge resources, providing the impetus for the growth of the cluster and enterprises.

\section{Environment of Cluster}

The construction and operation of knowledge transfer network in cluster is always closely related with cluster environment and interaction. In favorable environment conducive to knowledge transfer, knowledge transfer between different actors in CCJQ can easily create an effective atmosphere of knowledge innovation. CCJQ environment includes soft environment and hard environment. Hard environment of cluster is the infrastructures which ensure and maintain the normal operation of CCJQ, such as transportation conditions, communication information equipment, building facilities, etc. Soft environment of cluster is the unwritten rules of environmental factors such as the system, the rules and customs, including social culture environment, system rules environment and human resources environment.

\section{COUNTERMEASURES TO PROMOTE INTERNAL} KNOWLEDGE TRANSFER OF CREATIVE INDUSTRIAL CLUSTER

\section{A. Forming Harmonious Environment and Atmosphere with Cluster as the Carrier}

Firstly, by building many forms of different industry carrier such as CBD, creative district, industry base, professional park and etc, government should provide the necessary working and living environment for knowledge exchanges between creative talents, enterprises and other institutions, to improve the infrastructure in CCJQ. Cultivating and creating CCJQ is the ideal way to promote new ideas and to create the new knowledge. Secondly, government should strive to cultivate the free, open knowledge innovation atmosphere in different types of 
CCJQ, and provide the conditions for creative formation and knowledge exchange in cluster through the methods such as knowledge BBS, exhibition, technology and property right exchange and other forms [8].

\section{B. Increasing Government Investment and Promoting Cluster Construction}

First, it is important to increase financial support for development of CCJQ, to expand the scale of Culture Creative Industry Special Funds. And government should take income tax relief, rewards and other forms to guide and encourage more intervention of social fund, and promote risk investment, pledge loan, venture investment and other funds in order to support development of CCJQ. Secondly, government should consider the reputation as the core to build the brand of culture creative enterprise and industry cluster, and introduce brands of creative enterprises with high reputation. Meanwhile, government needs to encourage the development of local creative enterprises, and cultivate the unified brand of CCJQ.

\section{Cultivating Industrial Chain}

Firstly, CCJQ should pay attention to the correlation effects between industries lying in different phases, and establish close contact among the culture creative product designers, manufacturers, distributors, dealers and other actors. Secondly, CCJQ should spread concentration and diffusion effect in CCJQ, and form specialized division of labor and cooperation. At last, CCJQ should extend the competitive segments of value chain of creative industry, and firmly grasp two high value-added sectors of culture creative product, that is, R\&D and marketing.

\section{Strengthening Platform of Public Service in Creative Industrial Cluster}

First of all, it's necessary to establish regular technical communication system in CCJQ. Some forms of cooperation and coordination, such as co-designing and intellectual property protection, should be conventionalization and institutionalized among culture creative enterprises, universities and research institutes, intermediary agencies and financial institutions. And CCJQ also should make full use of scientific research resources in cluster. Second, managers of CCJQ should strengthen intermediary service organization construction, and provide various services for culture creative enterprises, like technical support, information service and decision aid.

\section{ACKNOWLEDGMENT}

This research is supported by Social Science Foundation of BIGC- - "Study on promoting innovative capacity of cultural creative industrial cluster: measures, mechanism and coordination” item.

\section{REFERENCES}

[1] Tsai W. P., "Knowledge transfer in intra-organizational networks: effects of network position and absorptive capacity on business unit innovation and performance, ” Academy of Management , 2001, 44: 996-1004.

[2] Luciana Lazzeretti, Rafael Boix and Francesco Capone, "Do creative industries cluster? Mapping creative local production systems in Italy and Spain,” Industry and Innovation, 2008, 15(5): 549-567.

[3] Davenport, T.H. and Prusak, L. , Working knowledge: how organizations manage what they know, Harvard Business School Press: Boston, MA, 1998.

[4] Polanyi, M. The tacit dimension, New York: Garden City, 1966.

[5] Argote, L., and Ingram, P., "Knowledge transfer: a basis for competitive advantage in firms", Organizational Behavior and Human Decision Processes, 2000, 82: 150-169.

[6] Dyer, J. H. and Nobeoka, K., "Creating and managing a highperformance knowledge-sharing network: the Toyota case," Strategic Management Journal, 2000,21: 245-267.

[7] Nonaka, I., "A dynamic theory of organizational knowledge creation, ” Organization Science, 1994, 5(1): 14-36.

[8] Nahapiet, J. and Ghoshal, S., "Social capital, intellectual capital, and the organizational advantage", Academy of Management Review, 1998, 23(2): 242-266. 